ARTICLE

Received 26 Jun 2012 | Accepted 26 Feb 2013 | Published 3 April $2013 \quad$ DOl: 10.1038/ncomms2649

\title{
Photochemical activity of Titan's low-altitude condensed haze
}

Murthy S. Gudipati, ${ }^{1,2}$, Ronen Jacovi ${ }^{1, \dagger}$, Isabelle Couturier-Tamburelli ${ }^{3}$, Antti Lignell ${ }^{1, \dagger} \&$ Mark Allen ${ }^{1,4}$

Titan, the largest moon of Saturn and similar to Earth in many aspects, has unique orangeyellow colour that comes from its atmospheric haze, whose formation and dynamics are far from well understood. Present models assume that Titan's tholin-like haze formation occurs high in atmosphere through gas-phase chemical reactions initiated by high-energy solar radiation. Here we address an important question: Is the lower atmosphere of Titan photochemically active or inert? We demonstrate that indeed tholin-like haze formation could occur on condensed aerosols throughout the atmospheric column of Titan. Detected in Titan's atmosphere, dicyanoacetylene $\left(\mathrm{C}_{4} \mathrm{~N}_{2}\right)$ is used in our laboratory simulations as a model system for other larger unsaturated condensing compounds. We show that $\mathrm{C}_{4} \mathrm{~N}_{2}$ ices undergo condensed-phase photopolymerization (tholin formation) at wavelengths as long as $355 \mathrm{~nm}$ pertinent to solar radiation reaching a large portion of Titan's atmosphere, almost close to the surface.

\footnotetext{
${ }^{1}$ Jet Propulsion Laboratory, Science Division, California Institute of Technology, 4800 Oak Grove Drive, Pasadena, California 91109, USA. ${ }^{2}$ IPST, University of Maryland, College Park, Maryland 20742, USA. ${ }^{3}$ Laboratoire Physique des interactions ioniques et moléculaires, UMR CNRS 7345, Aix-Marseille Université, 13397 Marseille cedex 20, France. ${ }^{4}$ Division of Geological and Planetary Sciences, California Institute of Technology, Pasadena, California 91125, USA. $\dagger$ Present addresses: Flight Control Group, Urban Aeronautics LTD, Nahal-Snir 10, Yavne 81224, Israel (R.J.); Arthur Amos Noyes Laboratory of Chemical Physics, California Institute of Technology, MC 127-72 1200 East California Boulevard, Pasadena, California 91125, USA (I.C.-T.). Correspondence and requests for materials should be addressed to M.S.G. (email: murthy.gudipati@jpl.nasa.gov).
} 
T itan, an orange-yellow coloured moon of Saturn, is unique in many ways. It is the second largest moon in our solar system and the only moon with a significant atmosphereenriched with organics, in the atmosphere and on the surface. Unlike Earth, Titan's atmosphere is oxygen-deficient, but instead dominated by nitrogen $(>90 \%)$ and methane $(\sim 5 \%)$. Organics on Titan originate from photochemistry of $\mathrm{N}_{2}$ and $\mathrm{CH}_{4}$ in Titan's upper atmosphere, initiated by solar wind particles and solar ultraviolet radiation. The earlier Voyager ${ }^{1}$ and the current Cassini-Huygens ${ }^{2-4}$ missions have provided tremendous insight into the atmosphere, aerosols and the surface-lakes, flows and dunes.

The processes that control the observed Titan's haze are still not well understood; in particular, at what altitudes the haze formation occurs. Pioneering laboratory studies showed that polymeric organic material, called tholins ${ }^{5,6}$, formed in dischargedriven reactions involving nitrogen, methane and other atmospheric compounds have optical properties similar to what had been deduced from observations of the Titan's haze. Please note that 'tholins' are laboratory analogues of Titan's haze particles, not the haze itself. Larger organics are currently thought to form high in Titan's atmosphere at altitudes above $800 \mathrm{~km} \mathrm{(ref.} \mathrm{7),} \mathrm{grow} \mathrm{through} \mathrm{coagulation} \mathrm{in} \mathrm{the} \mathrm{lower}$ atmosphere down to $500 \mathrm{~km}$ (refs 8-10), and finally rain down onto the surface. It has been suggested that ultraviolet-induced chemical processing (aging and hardening) of these aerosols can occur via solid-state polymerization ${ }^{11,12}$. Other observations and modelling studies infer that about $60 \%$ of the total column mass production of tholin-like aerosols may occur below $300 \mathrm{~km}$ (ref. 13) and that the production of large macromolecular particles peaks at $\sim 100 \mathrm{~km}$ (ref. 14). This production includes condensation of simpler unsaturated organic compounds onto the larger haze particles at these cold low altitudes ${ }^{15}$.

Below $\sim 600 \mathrm{~km}$, the gas composition and organic haze of Titan's atmosphere significantly attenuate the greater part of high-energy electron, ion and photon radiation ${ }^{16}$. However, at longer wavelengths the solar spectrum is not significantly attenuated in Titan's atmosphere until the $100 \mathrm{~km}$ altitude level is reached ${ }^{17}$. For example, $\sim 99 \%$ of photons at wavelengths $>220 \mathrm{~nm}$ make it through to lower altitudes ${ }^{14,18}$. The solar flux at $220 \mathrm{~nm}$ is estimated to be $\sim 1 \times 10^{10}$ photons $\mathrm{cm}^{-2} \mathrm{~nm}^{-1} \mathrm{~s}^{-1}$ at $200 \mathrm{~km}$, and at the same altitude the estimated solar flux at $350 \mathrm{~nm}$ is $\sim 3 \times 10^{11}$ photons $\mathrm{cm}^{-2} \mathrm{~nm}^{-1} \mathrm{~s}^{-1}$. The solar flux at $350 \mathrm{~nm}$ and at $200 \mathrm{~km}$ altitude is comparable to the upper atmosphere radiation field at shorter wavelengths that is important for inducing gas-phase upper atmospheric photochemistry. Even at lower altitudes (for example, at $70 \mathrm{~km}$ ) the photon flux is not insignificant at both these wavelengths $\left(\sim 8 \times 10^{7}\right.$ photons $\left.\mathrm{cm}^{-2} \mathrm{~nm}^{-1} \mathrm{~s}^{-1}\right)$. Thus, photochemical reactions that may occur in lower atmosphere $(<600 \mathrm{~km})$ involving longer wavelength solar photons $(>200 \mathrm{~nm}$ ) will have a significant role to play in Titan's atmosphere and its photochemical evolution.

Titan's unusual dense and oxygen-depleted atmosphere has a wide variety of linear unsaturated polyynes-nitrogen-containing polycyanoacetylenes ${ }^{19}$, such as $\mathrm{C}_{4} \mathrm{~N}_{2}$ as well as polyacetylenes ${ }^{20}$ and aromatic molecules ${ }^{21}$-that undergo photopolymerization forming complex tholin-like molecules, whose structure is still under intense investigation ${ }^{22}$. Recent laboratory studies showed that when these tholins come into contact with oxygen-bearing molecules such as water (surface/subsurface ice on Titan), result in the formation of complex prebiotic molecules such as amino acids $^{5}$ and nucleobases ${ }^{23,24}$. Thus, atmospheric aerosol photochemistry has a key role in the processes leading to the potential prebiotic chemistry on Titan's surface ${ }^{25}$.

As photoabsorption of condensed molecules can occur at longer wavelengths due to polarizability of condensed phase $e^{26}$ exciton interactions ${ }^{27,28}$ and spin-orbit coupling ${ }^{29}$, compared with their isolated molecular counterparts, the absorption of longer wavelength photons may trigger solid-state chemical processes with a sufficient yield to significantly affect low-altitude particle composition. Solid-state organic photochemistry could continue to altitudes as low as $50 \mathrm{~km}$ or below, leading to progressive conversion of Titan's aerosols to complex polymeric organic material during the rain-down process.

The three possible phases of organics in Titan's atmosphere are schematically shown in Fig. 1. Our laboratory studies presented here model the condensed small linear organic molecules that form a class of polyynes observed on Titan. While preparing a mixture of various possible polyynes and cyanopolyynes, as shown in Fig. 1, would be a challenging task, the photochemical principles that govern these mixed monomers can be illustrated in the chemistry of one of these components alone, hence our choice to study single monomer condensates. Voyager 1 provided the first detection of crystalline organic ice in the Titan's atmosphere-dicyanoacetylene $\left(\mathrm{C}_{4} \mathrm{~N}_{2}\right)$-that confirmed the model expectation for gas condensation ${ }^{30,31}$, which prompted a series of laboratory work on $\mathrm{C}_{4} \mathrm{~N}_{2}$ in late 1990s (refs 32,33). Solidstate photopolymerization of these atmospheric ice condensates could be an important low-altitude source of macromolecular organic tholin-like material. The lower the altitude, the longer would be the wavelength of photons that could be causing photochemical activity in Titan's atmosphere-all the way to the surface. Our laboratory simulations presented here show that photopolymerization of condensed unsaturated Titan's volatiles indeed occurs at wavelengths at least as long as $355 \mathrm{~nm}$. We conclude that contrary to the present understanding that Titan's lower atmosphere is inert, our studies presented here show that
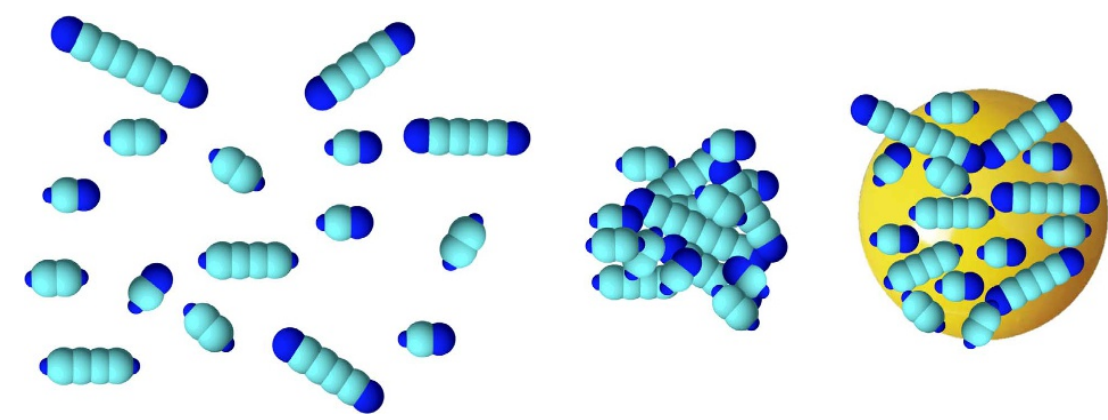

Figure 1 | Three phases of molecules in Titan's atmosphere. Small molecules in Titan's atmosphere could exist as isolated entities in the gas phase (left), condensed small molecules (middle) or accreted onto a larger aerosol particle (right). Gas-phase photochemistry is controlled by the molecular spectroscopic properties of the isolated molecules. In both condensed phases, additional photochemical pathways are triggered as detailed in the text. 
Titan's atmosphere is photochemically active even at lower altitudes and leads to the formation of complex tholin-like potential prebiotic molecules due to the penetrating longer wavelength photons. This is consistent with observations of Titan's haze stretching between $\sim 500 \mathrm{~km}$ and $\sim 50 \mathrm{~km}$ above the surface $^{9}$, containing several regions of haze $(0, A, B$ and $C)$ as recently characterized by the Cassini CIRS instrument ${ }^{34,35}$.

\section{Results}

Long-wavelength Titan aerosol analogue photochemistry. We developed a laboratory study to investigate whether solid-state polymerization of large unsaturated organic molecules condensed on Titan's aerosols could be induced by the photons $(>220 \mathrm{~nm}$ ) that still could penetrate through its atmosphere to low altitudes. For this simulation we chose $\mathrm{C}_{4} \mathrm{~N}_{2}$ given its known presence in Titan's lower atmosphere ${ }^{30}$. Therefore, it also could serve as a model for other large condensed unsaturated organic compounds, particularly long linear chains of alternating single and multiple bonds, which are formed in this atmosphere. In the condensed phase, their interactions will be similar-whether between molecules with same molecular formula such as $\mathrm{C}_{4} \mathrm{~N}_{2}$ or a statistical distribution of a wide variety of molecules with varying chain lengths. As illustrated in Fig. 2 (top), the ultraviolet absorption spectrum of $\mathrm{C}_{4} \mathrm{~N}_{2}$ ice at $100 \mathrm{~K}$ has structure at $<300 \mathrm{~nm}$ in agreement with the gas-phase spectrum ${ }^{36-39}$, but also a featureless long-wavelength absorption stretching to $>360 \mathrm{~nm}$, beyond where the gas-phase absorption ends. The broad continuum absorption at longer wavelengths than $\sim 350 \mathrm{~nm}$ could be due to the weak singlet-triplet absorption amplified in the condensed phase, in agreement with detection of phosphorescence from the first triplet $\left(T_{1}\right)$ state of $\mathrm{C}_{4} \mathrm{~N}_{2}$ at $\sim 390 \mathrm{~nm}$ (ref. 40).

Details of the laboratory simulation apparatus are summarized in Methods and further details are available in the Supplementary Material for this article. Laser photolysis experiments at the Jet Propulsion Laboratory were conducted at three wavelengths: 532,355 and $266 \mathrm{~nm}$, which were obtained by second, third and fourth harmonic generation of a 5-ns pulsed Nd-YAG. Photon fluxes used in these experiments were typically $\sim 1 \times 10^{17}$, $\sim 3 \times 10^{16}$ and $\sim 5 \times 10^{16}$ photons $\mathrm{cm}^{-2} \mathrm{~s}^{-1}$ at 532,355 and $266 \mathrm{~nm}$, respectively. To avoid multiphoton processes, the initial laser beam of $\sim 3 \mathrm{~mm}$ diameter was expanded to $\sim 20 \mathrm{~mm}$ using a $10-\mathrm{cm}$ focal-length quartz lens. The experiments were designed to conserve the $\mathrm{C}_{4} \mathrm{~N}_{2}$ that was difficult to synthesize. The $\mathrm{C}_{4} \mathrm{~N}_{2}$ ice sample was first irradiated with the $532 \mathrm{~nm}$ laser for several hours at $\sim 0.15 \mathrm{~W} \mathrm{~cm}^{-2}$ flux. No detectable change in the infrared spectra $\left(2,244 \mathrm{~cm}^{-1}\right)$ was observed from the photolysis at this wavelength. The same $\mathrm{C}_{4} \mathrm{~N}_{2}$ ice was then subjected to $355 \mathrm{~nm}$ irradiation, which resulted in depletion of $\sim 7 \%$ of the infrared absorption over $8 \mathrm{~h}$ of irradiation. As the degree of processing due to $355 \mathrm{~nm}$ irradiation was small, the same sample was then exposed to the $266 \mathrm{~nm}$ laser beam, which resulted in significantly more (a total of $\sim 50 \%$ ) depletion of the infrared absorption. In subsequent experiments, the $532 \mathrm{~nm}$ irradiation was omitted. We are confident that, although laserdesorption as a competing process could not be completely ruled out, it is not the dominant process. If it were, one should observe only a decrease in the monomer band and not an increase in the broad absorption that persists even after sublimation of the monomer $\mathrm{C}_{4} \mathrm{~N}_{2}$. We also conducted several control experiments where the $\mathrm{C}_{4} \mathrm{~N}_{2}$ ices were (a) not irradiated, (b) only irradiated with $355 \mathrm{~nm}$ laser, and (c) only irradiated with $266 \mathrm{~nm}$ laser. Unirradiated $\mathrm{C}_{4} \mathrm{~N}_{2}$ films did not yield a residue on warm-up. Irradiation only with $266 \mathrm{~nm}$ laser resulted in similar photopolymerization process as with $355 \mathrm{~nm}$ irradiation before the $266 \mathrm{~nm}$ irradiation.

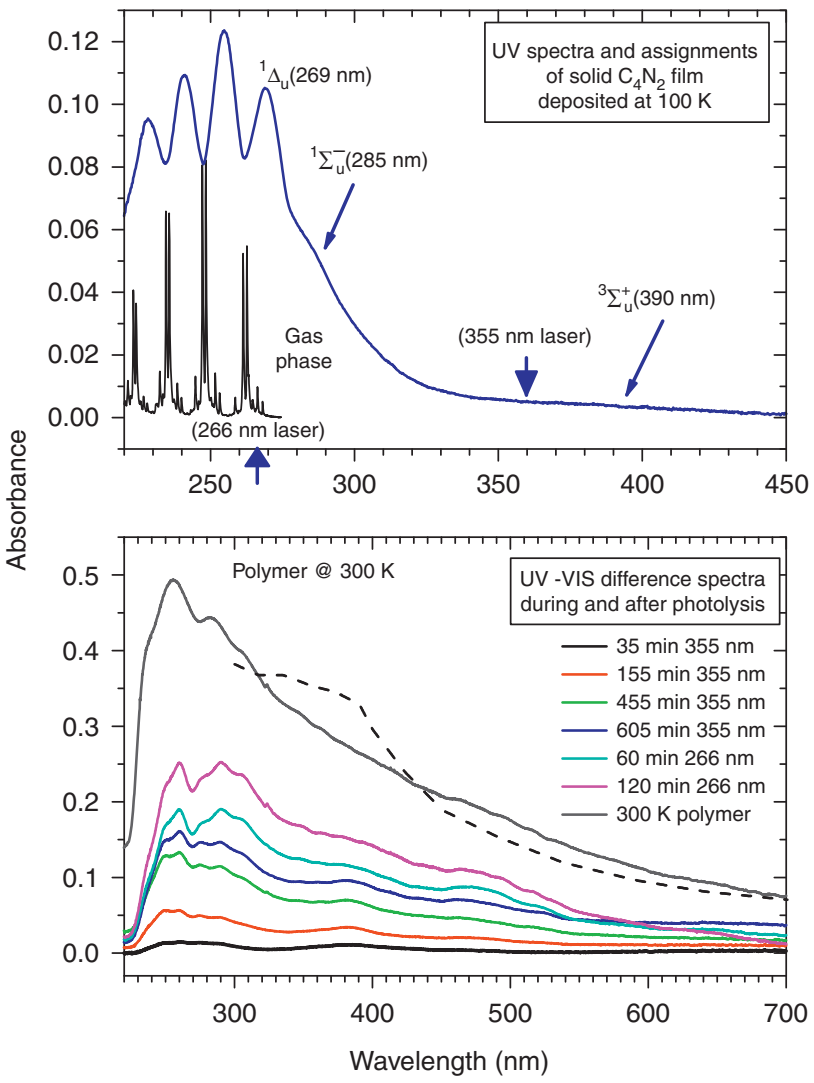

Figure 2 | Ultraviolet-visible spectra of dicyanoacetylene ice and its photoproduct tholin. Top: ultraviolet-visible absorption spectra of dicyanoacetylene $\left(\mathrm{C}_{4} \mathrm{~N}_{2}\right)$ solid films condensed at $100 \mathrm{~K}$ on a sapphire window. The gas-phase ultraviolet absorption spectrum of $\mathrm{C}_{4} \mathrm{~N}_{2}$ (ref. 39) is shown as black curve for comparison. Bottom: ultraviolet-visible absorption difference spectra obtained by subtracting the spectrum taken before laser photolysis from the spectra measured, first during photolysis at $355 \mathrm{~nm}$, then followed by photolysis at $266 \mathrm{~nm}$. Sample temperature was kept at $100 \mathrm{~K}$ during irradiation and then, subsequent to irradiation, warmed up to $300 \mathrm{~K}$ under vacuum (shifted curve on the top). The ultraviolet spectrum of the residual polymer (top curve) does not change significantly between 180 and $300 \mathrm{~K}$, and it is similar to that of the conventional tholin (shown as dashed line) reported by Sagan and Khare ${ }^{6}$. Spikes and wiggles in the red curve at $\sim 500 \mathrm{~nm}$ are artefacts from the ultraviolet lamp profile.

In both $266 \mathrm{~nm}$ laser and mercury ( $\mathrm{Hg}$ ) lamp photolysis experiments, the latter carried out at the University of Provence, France, the photopolymer remaining at room temperature under vacuum was similar-an orange-brown non-volatile film. A photograph of the experimental photopolymerized aerosol analogue made at the Jet Propulsion Laboratory is shown in Fig. 3. The structured vibronic absorption of condensed $\mathrm{C}_{4} \mathrm{~N}_{2}$ ice in the ultraviolet $(200-300 \mathrm{~nm})$ decreases during $355 \mathrm{~nm}$ irradiation due to photopolymerization, whereas the broad and structure-less absorption increases, indicating photoproduct absorption/scattering to be stronger than the monomer $\mathrm{C}_{4} \mathrm{~N}_{2}$ absorption in the ultraviolet. This trend continues with $266 \mathrm{~nm}$ laser photolysis (Fig. 2, bottom). Differencing spectra taken before and after the initiation of irradiation at each wavelength reveals the extent of sample processing. As shown in Fig. 4 (top), photolysis at $355 \mathrm{~nm}$ results in depletion of the $2,244 \mathrm{~cm}^{-1}$ band and an increase of a broader absorption around the depleted peak, also due to $\mathrm{CN}$ stretching of the polymer (Fig. 4, top inset). Irradiation at $266 \mathrm{~nm}$ resulted in a significant decrease of 


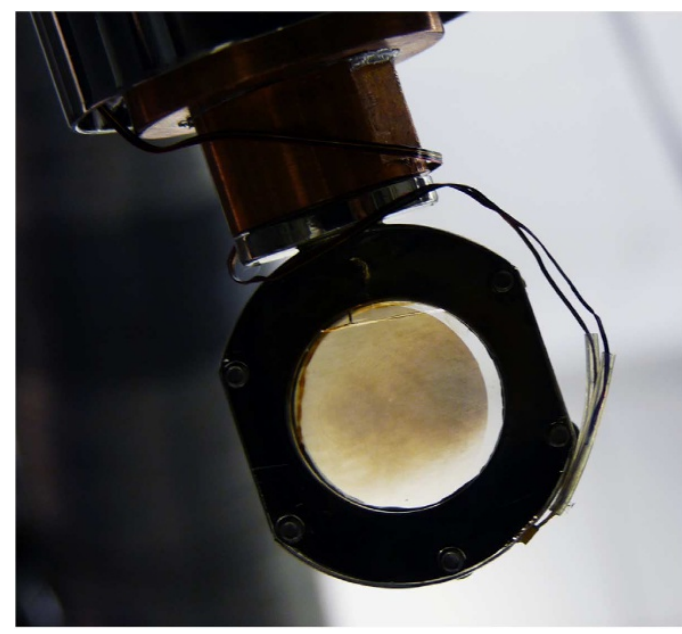

Figure 3 | Photochemically produced tholin under simulated Titan's lower atmospheric conditions. Photograph of the non-volatile polymeric residue film remaining on the sapphire substrate window after warmup to $300 \mathrm{~K}$ under vacuum. This residue was formed during the laser photolysis of condensed $\mathrm{C}_{4} \mathrm{~N}_{2}$ molecules at $266 \mathrm{~nm}$ at the Jet Propulsion Laboratory (JPL). Similar orange-brown tholin-like non-volatile polymeric residues were observed during several similar experiments at JPL and the University of Provence, France.

monomer absorption at $2,244 \mathrm{~cm}^{-1}$, but the increase in the broad absorption was not relatively as significant as in the $355 \mathrm{~nm}$ photolysis (Fig. 4, middle).

Nature of the photopolymer. During warm-up under vacuum, spectral features of non-volatile photopolymer emerge in the ultraviolet and infrared spectra at temperatures beyond the sublimation temperature of $\mathrm{C}_{4} \mathrm{~N}_{2}(\sim 160 \mathrm{~K})$ to room temperature. The polymer should be forming even at $100 \mathrm{~K}$ during photolysis or between 100 and $160 \mathrm{~K}$ during the warm-up, but its spectral signatures, as they are broad, are obscured by monomer spectra before the monomer sublimes at $\sim 160 \mathrm{~K}$ (Supplementary Fig. S1). For purposes of confirmation, we performed a similar $\mathrm{C}_{4} \mathrm{~N}_{2}$ ice irradiation at the University of Provence (Marseille, France), using a conventional high-pressure Hg-lamp equipped with a $<300 \mathrm{~nm}$ cutoff filter. The results obtained were very similar to the $355 \mathrm{~nm}$ laser irradiation experiments, as can be seen from the infrared spectra shown in Fig. 4 (bottom). The differences in the polymer absorption maximum when irradiated with the $266 \mathrm{~nm}$ laser $\left(2,215 \mathrm{~cm}^{-1}\right)$ or with the $\mathrm{Hg}$ lamp at $>300 \mathrm{~nm}$ $\left(2,230 \mathrm{~cm}^{-1}\right)$, shown in Fig. 4 , could be due to the difference in reaction pathways accessible for photons below $280 \mathrm{~nm}$ versus above $300 \mathrm{~nm}$. The structure-less ultraviolet spectrum resembles more closely the tholin ultraviolet-visible spectra reported by Sagan and Khare ${ }^{6}$, shown as dashed curve in Fig. 2, than the spectra of Imanaka et al. ${ }^{41}$ On the other hand, Fourier transform infrared (FTIR) spectra in the $4,000-1,600 \mathrm{~cm}^{-1}$ region are similar (Fig. 5) to the infrared spectra of discharge-generated polymer reported by Imanaka et al. ${ }^{41,42}$ In spite of the difference in preparation methods (gas-phase discharge at various pressures versus condensed-phase photochemistry) and the initial conditions $\left(\mathrm{N}_{2}+\mathrm{CH}_{4}\right.$ versus $\left.\mathrm{C}_{4} \mathrm{~N}_{2}\right)$, these qualitative similarities in the optical properties of the non-volatile polymer (tholin) reveal that these materials have very similar chemical structures. The actual structural properties of tholins are not known and are expected to be diverse, both at the molecular structure (chemical bonding) level and at the supramolecular structure (three-dimensional polymer structures) level. We prefer

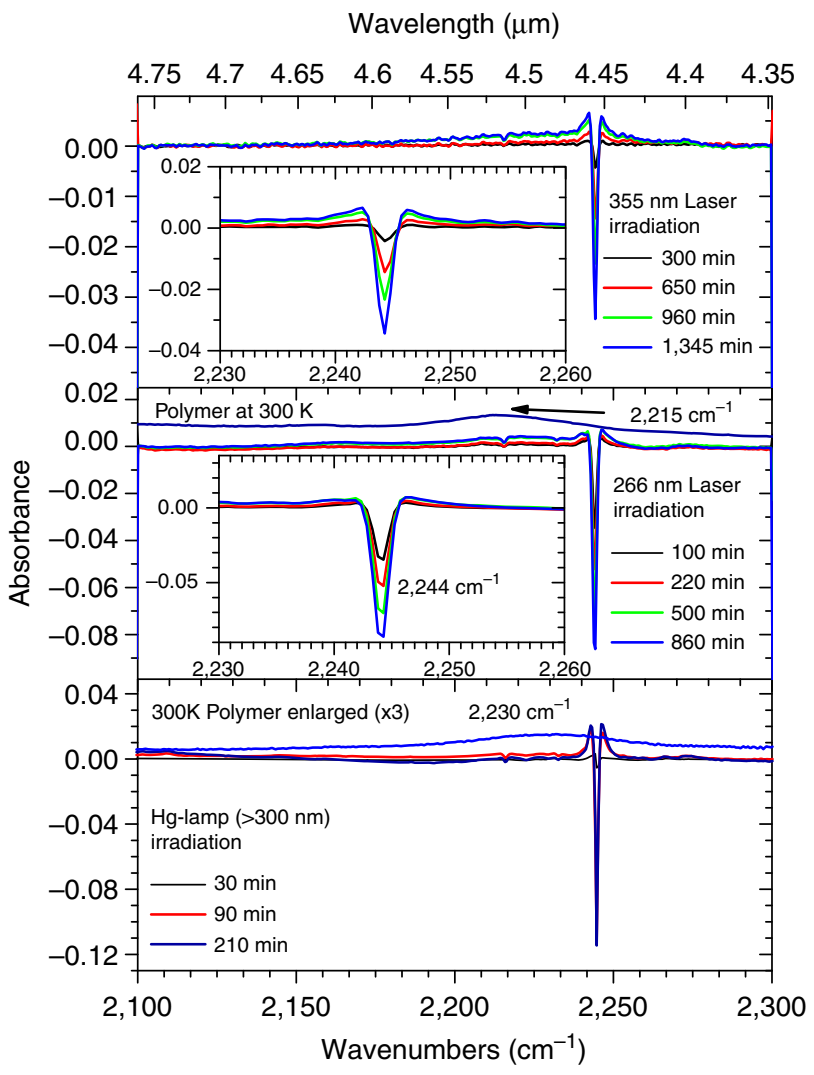

Figure 4 | Infrared spectra of dicyanoacetylene ice and their changes during laser photolysis. Results of the laser irradiation experiments conducted at the Jet Propulsion Laboratory (top and middle) and Hg-lamp irradiation experiments conducted at the University of Provence, France (bottom). The polymer residual spectra (middle and bottom boxes) were referenced to background spectra taken before $\mathrm{C}_{4} \mathrm{~N}_{2}$ was deposited, whereas all the other spectra show differences between the spectra after irradiation at the specified wavelength and duration and the spectra before irradiation. Negative absorbance means depletion of the spectral feature. Positive absorbance is due to the appearance of a new spectral feature. Top: laser photolysis at $355 \mathrm{~nm}$. Depletion of the absorption at $2,244 \mathrm{~cm}^{-1}$ and increase in polymer/intermediate photoproducts absorption (broad 2,235$2,250 \mathrm{~cm}^{-1}$ ) can clearly be seen. Middle: laser photolysis at $266 \mathrm{~nm}$ resulting in more significant depletion. Broad $2,215 \mathrm{~cm}^{-1} \mathrm{CN}$ stretching band, measured at $300 \mathrm{~K}$ after warm-up, is the infrared spectrum for the orange-brown coloured non-volatile polymer (Fig. 3). Bottom: high-pressure Hg-lamp photolysis (photons $<300 \mathrm{~nm}$ filtered out) showing spectra similar to $355 \mathrm{~nm}$ laser photolysis (top panel).

not to over interpret these data, but to show that tholins-though could have similar spectral properties may have diverse molecular and supramolecular aerosol structures.

In the condensed phase, in addition to normal spin-allowed ultraviolet absorption, photochemical reactions can also occur through absorption of light at longer wavelengths directly into the triplet-excited states, which have strong radical character. In the case of $\mathrm{C}_{4} \mathrm{~N}_{2}$, the spin-allowed ultraviolet absorption occurs at $<300 \mathrm{~nm}$ and spin-forbidden absorption occurs at $>300 \mathrm{~nm}-$ hence very efficient photodepletion of monomer at $266 \mathrm{~nm}$ compared to irradiation at $355 \mathrm{~nm}$ (Fig. 2). Larger unsaturated organics condensed onto aerosols likely have both spin-allowed strong and spin-forbidden (condensed-phase enhanced) weak photoabsorptions and similar solid-state photoprocessing potential. It is known that gas-phase $\mathrm{C}_{4} \mathrm{~N}_{2}$ could dissociate with $248 \mathrm{~nm}$ light ${ }^{43,44}$ resulting in the formation of $\mathrm{CN}$ and the CCCN 


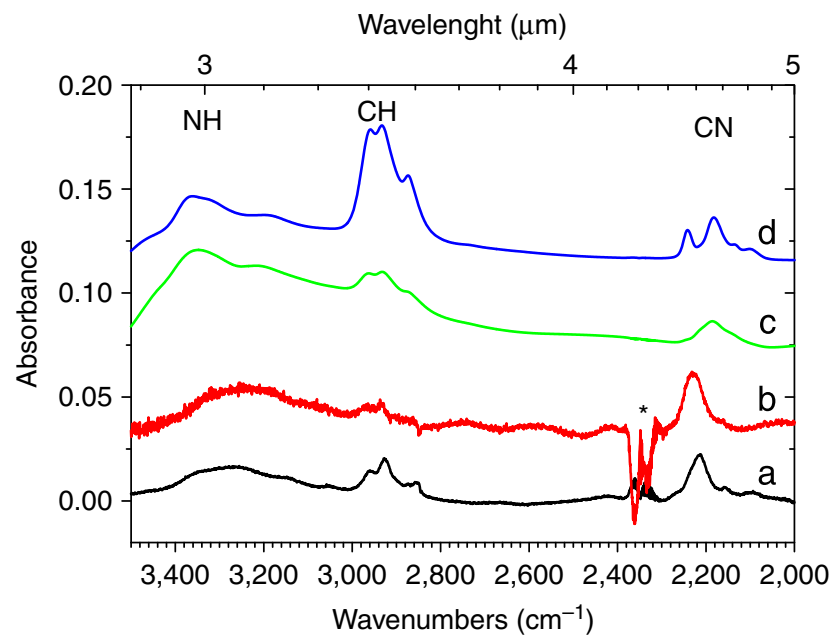

Figure 5 | A comparison of the infrared spectra of tholins synthesized in the gas and condensed phases. Infrared spectra of tholin-like photopolymers at room temperature compared with tholins made from conventional discharge experiments by Imanaka 41,42 . Method of preparation of tholin, bottom to top (a-d): JPL $266 \mathrm{~nm}$ laser photolysis (a); Marseille $\mathrm{Hg}$ lamp (>300 nm) pholysis (b); 10\% methane in nitrogen discharge ${ }^{41}$ at $26 \mathrm{~Pa}$ (c) and at $160 \mathrm{~Pa}$ (d). An excellent comparison between longer wavelength photochemical polymer spectra (JPL: $266 \mathrm{~nm}$; Marseille $>300 \mathrm{~nm}$ ) and with the discharge-made tholins spectra can be seen. In our spectra the ratio of $\mathrm{CN}$ to $\mathrm{CH}$ and $\mathrm{NH}$, band strengths is different (more $\mathrm{CN}$ ) compared to Imanaka's data, because in our experiments far-less hydrogen is available (either as traces of $\mathrm{H}_{2} \mathrm{O}$ impurity, or intentionally added $\mathrm{H}_{2} \mathrm{O}$ or other hydrocarbons such as $\mathrm{CH}_{4}$ or $\mathrm{C}_{2} \mathrm{H}_{2}$ ). ${ }^{\star}$ Gas-phase $\mathrm{CO}_{2}$ residual absorption.

radicals. Hence, the $266 \mathrm{~nm}$ photochemistry is likely to be controlled by dissociation products.

\section{Discussion}

Results discussed above indicate that singlet-triplet absorptiondriven $(355 \mathrm{~nm}$ irradiation) photochemical processes involves triplet $\mathrm{C}_{4} \mathrm{~N}_{2}$ molecules reacting with other $\mathrm{C}_{4} \mathrm{~N}_{2}$ molecules in its surrounding, resulting in the formation of the photopolymer (Fig. 6), whose $\mathrm{CN}$ stretching vibrational absorption remains around $2,244 \mathrm{~cm}^{-1}$, but is much broader. Upon warm-up this band shifts to $2,225 \mathrm{~cm}^{-1}$, once the monomer is sublimed above $160 \mathrm{~K}$. On the other hand, singlet-excitation-driven $(<280 \mathrm{~nm})$ photochemical processes result in molecular dissociation of $\mathrm{C}_{4} \mathrm{~N}_{2}$ into $\mathrm{C}_{3} \mathrm{~N}$ and $\mathrm{CN}$ radicals as well as photopolymerization (Fig. 6). The dissociation products recombine and react with other molecules during the warm-up until the monomer $\mathrm{C}_{4} \mathrm{~N}_{2}$ sublimes, at which time the polymer absorption $\sim 2,215 \mathrm{~cm}^{-1}$ can clearly be seen. These mechanisms, qualitatively highlighted in Fig. 6, would be applicable to mixed cyanopolyynes and polyynes, known to be present in Titan's atmosphere. Both ultraviolet and infrared spectra of the polymer do not change significantly between 180 and $300 \mathrm{~K}$, once the volatile monomer has evaporated above $160 \mathrm{~K}$. Slight shifts in the broad absorption maxima of the polymer in $266 \mathrm{~nm}$ laser, $355 \mathrm{~nm}$ laser and $>300 \mathrm{~nm}$ Hg-lamp studies, $2,215 \mathrm{~cm}^{-1}, \quad 2,225 \mathrm{~cm}^{-1}$, $2,230 \mathrm{~cm}^{-1}$, respectively, could be due to different local environments around the $-\mathrm{CN}$ functional group of the photopolymer. It is known that the $\mathrm{CN}$ stretching frequency shifts based on the structural environment around it-less or more polar and less or more hydrogen bonding ${ }^{45}$.

In our studies presented here, during the photolysis and warmup, additional reactions with traces of $\mathrm{H}_{2} \mathrm{O}$ impurity, or intentionally added $\mathrm{H}_{2} \mathrm{O}$, or other hydrocarbons such as $\mathrm{CH}_{4}$ or $\mathrm{C}_{2} \mathrm{H}_{2}$, result in the formation of $\mathrm{CH}$ and $\mathrm{NH}$ functional groups into the polymer, whose spectra at room temperature are very similar to the tholin infrared spectra made from conventional discharge experiments ${ }^{41}$ (Fig. 5). Based on this observation, we conclude that the intermediate photoproducts are very reactive towards hydrogen-containing molecules. Though water is sparse, hydrocarbons are abundant on Titan and similar photochemical processes are expected to occur in the Titan's atmosphere.

In addition, we investigated the efficiency of photoprocessing by monitoring the time evolution of the $\mathrm{C}_{4} \mathrm{~N}_{2}$ infrared absorption on irradiation at 355 and $266 \mathrm{~nm}$. Figure 7 shows the change in $\mathrm{C}_{4} \mathrm{~N}_{2}$ infrared absorption with exposure time. The change during $355 \mathrm{~nm}$ irradiation is linear with photon flux (dose), indicating that the photochemistry is due to weak electronic transitions (singlet-triplet), falling in a small linear segment of a first-order reaction (only $\sim 13 \%$ depletion in $\sim 1,300 \mathrm{~min}$ ) that would have developed into a nonlinear exponential behaviour on prolonged photolysis. Continuing with the photolysis at $266 \mathrm{~nm}$ resulted in more rapid depletion of $\mathrm{C}_{4} \mathrm{~N}_{2}$, following a single exponential behaviour, in accordance with first-order exponential process ${ }^{46}$ (a total of $\sim 48 \%$ depletion after 860 min irradiation at $266 \mathrm{~nm}$ ).

We also conducted experiments to rule out the possibility whether multiphoton processes could have resulted in the observed photochemistry. The experiments conducted in France were conducted using a $150 \mathrm{~W}$ high-pressure Mercury lamp that was flooded (without focusing) on the sample after cutting out the shorter wavelengths below $300 \mathrm{~nm}$ using a glass filter. These results are very similar to the results from defocused laser irradiation. Further, we changed the pulse energy $\left(E_{\mathrm{L}}\right)$ of $355 \mathrm{~nm}$ laser by a factor of 3 (from 50 to $160 \mathrm{~mW} \mathrm{~cm}^{-2}$ before defocusing the laser), keeping the repetition rate at $20 \mathrm{~Hz}$. The photolysis yields $(\phi)$ plotted in the insert of Fig. 7 (after converting normalizing photon flux to time) fall linearly on the curve at the last three-irradiation points. Also plotted in Fig. 7 are the photolysis yields for $160 \mathrm{~mW} \mathrm{~cm}^{-2}$ irradiation (the last four points on the main curve). The slopes of these two curves give the photolysis yields per minute at these two laser fluencies. While a single-photon process follows the equation $(\phi)=k \times E_{\mathrm{L}}$; a twophoton process obeys a quadratic dependence $(\phi)=k^{\prime} \times\left(E_{\mathrm{L}}\right)^{2}$. Ratios of photolysis yields at two laser fluencies $E_{\mathrm{L} 1}$ and $E_{\mathrm{L} 2}$ should follow $\left(\phi_{1} / \phi_{2}\right)=\left(E_{\mathrm{L} 1} / E_{\mathrm{L} 2}\right)$ for single-photon process and $\left(E_{\mathrm{L} 1} / E_{\mathrm{L} 2}\right)^{2}$ for a two-photon process. The laser fluence ratio $(160 \mathrm{~mW} / 50 \mathrm{~mW})$ is 3.2 for single-photon and 10.24 for twophoton processes. The observed photolysis yield ratio $\left(\phi_{1} / \phi_{2}\right)$ of 3.15 (Fig. 7) clearly demonstrates that the photoabsorption and the photochemistry with $355 \mathrm{~nm}$ laser irradiation presented here are linear one-photon processes, not involving nonlinear multiphoton processes. Laser irradiation at $266 \mathrm{~nm}$ is done under similar conditions $\left(\sim 0.12 \mathrm{~W} \mathrm{~cm}^{-2}\right.$ before defocusing $)$ and we infer a single-photon-induced photochemical process at this wavelength as well.

Under our experimental conditions $\left(\sim 10^{-9}\right.$ mbar vacuum) $\mathrm{C}_{4} \mathrm{~N}_{2}$ starts to sublime around $160 \mathrm{~K}$. No sign of sublimation is detected at $100 \mathrm{~K}$. Based on these observations, for similar monomer molecules, we expect the sticking coefficient in Titan's atmosphere at much higher pressures and similar temperatures to be close to unity. Experimental data presented here demonstrate that solar radiation at wavelengths that penetrate deep into Titan's atmosphere, down to $200 \mathrm{~km}$ and below, can initiate a new source of tholin-like haze production from the condensates in this altitude range. As the sedimentation velocity in this region is very slow, of order $\sim 0.03 \mathrm{~cm} \mathrm{~s}^{-1}$ at $\sim 100 \mathrm{~km}$ altitude ${ }^{22}$, aerosol particles stay within the haze layer for $\sim 10$ Earth years or $\sim 3 \times 10^{8}$ s. Solar photon flux at $10 \mathrm{AU}$ is $\sim 14 \mathrm{~W} \mathrm{~m}^{-2}$ and photons between 200 and $350 \mathrm{~nm}$ constitute $\sim 5 \%$ of the total 


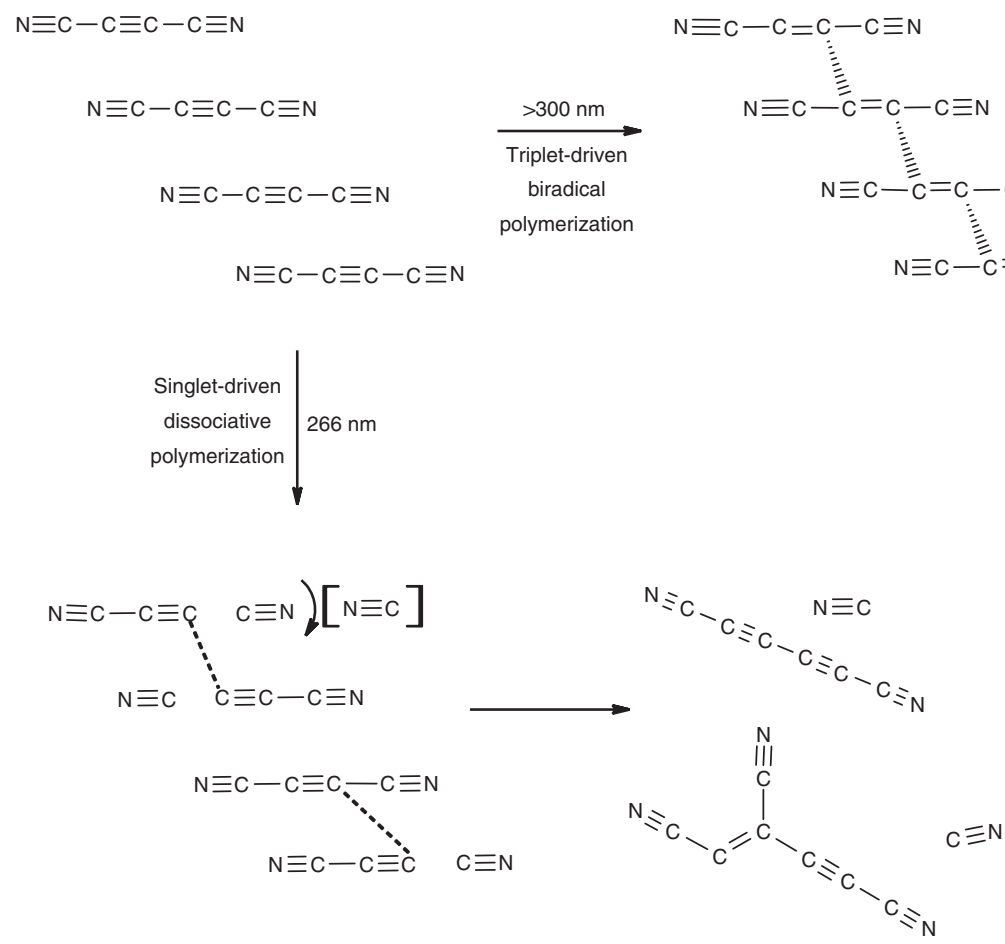

Figure 6 | Possible reaction pathways for longer wavelength production of tholins in condensed phase. Proposed mechanisms for the longer wavelength (ultraviolet-visible photons) triplet excitation-driven and shorter wavelength (ultraviolet photons) singlet-excitation-driven photopolymerization of $\mathrm{C}_{4} \mathrm{~N}_{2}$ in the condensed aerosol phase. Broken lines are not bonds, but represent new bond formation in progress. Radical centers are not specifically shown to avoid congestion in structures. While longer wavelengths result in more uniform polymerization, shorter wavelengths result in dissociation of parent $\mathrm{C}_{4} \mathrm{~N}_{2}$ to $\mathrm{C}_{3} \mathrm{~N}$ and $\mathrm{CN}$ radicals that react to form a wide distribution of polymers. In both cases, monomer molecules accreted on an existing aerosol particle (Fig. 1) could chemically bind to this haze particle, increasing its size and modifying it chemically on its surface-a process that could be critical to Titan's atmospheric chemistry, but not considered previously.

energy flux, resulting in $\sim 0.7$ or $7 \times 10^{-5} \mathrm{~W} \mathrm{~cm}^{-2}$ or $\sim 10^{14}$ photons $\mathrm{cm}^{-2} \mathrm{~s}^{-1}$ (over 200-350 nm) or $\sim 6 \times 10^{11}$ photons $\mathrm{cm}^{-2} \mathrm{~s}^{-1} \mathrm{~nm}^{-1}$. The laboratory dose was typically $0.15 \mathrm{~W} \mathrm{~cm}^{-2}$, which amounts to $\sim 2,000$ times more flux than received by Titan's atmosphere at these wavelengths. As seen in Fig. 7, photochemical polymerization at $355 \mathrm{~nm}$ of a condensed $\mathrm{C}_{4} \mathrm{~N}_{2}$ film ( $\sim 200 \mathrm{~nm}$ thick) is $\sim 13 \%$ over $1,340 \mathrm{~min}(84,000 \mathrm{~s})$ and $0.05 \mathrm{~W} \mathrm{~cm}^{-2}$ flux, which corresponds to $\sim 6 \times 10^{7} \mathrm{~s}$ on Titan, which is a factor of 5 less time that an aerosol particle spends in Titan's atmosphere. So significant photopolymerization processing in Titan's atmosphere is possible from weakly allowed spin-forbidden photoexcitations, resulting in solid-state radical reactions. On the other hand, photopolymerization due to $266 \mathrm{~nm}$ photons, caused by strongly allowed photoexcitation, occurs much faster, $\sim 35 \%$ yield over $860 \mathrm{~min}(21,600 \mathrm{~s})$ at $0.12 \mathrm{~W} \mathrm{~cm}^{-2}$, which corresponds to $\sim 4 \times 10^{7} \mathrm{~s}$ on Titan, an order of magnitude less than the residence time of aerosols in Titan's condensed haze layer. Based on these data we infer that significant photochemical polymerization is expected to occur involving spin-allowed strong ultraviolet absorption by Titan's aerosol molecules.

Chemical models predict the formation of unsaturated organic molecules even larger than $\mathrm{C}_{4} \mathrm{~N}_{2}$ in Titan's atmosphere ${ }^{47}$. As with $\mathrm{C}_{4} \mathrm{~N}_{2}$, the larger molecules will condense into ices in the lower atmosphere. The gas-phase spectra of such molecules will have absorption longward of the $\mathrm{C}_{4} \mathrm{~N}_{2}$ gas-phase absorption, and in condensed phase these absorption spectra would be shifted to even longer wavelengths. Therefore, solar radiation out to visible wavelengths penetrating to Titan's lower atmosphere may initiate production of photopolymerization of condensed organic aerosols not previously accounted for and can provide a mechanism for the majority of tholin formation predicted to occur at low altitudes. We conclude that Titan's lower atmosphere is more photochemically active than so far assumed. In addition, experimental results presented here can be extrapolated to shorter wavelength solar radiation at higher altitudes, exposure to which should lead to condensed-phase processing of accumulations of unsaturated organic molecules as previously suggested ${ }^{11,12}$. Thus, tholin-like haze formation occurs by a variety of different photo-initiated processes throughout the whole atmospheric column of Titan.

\section{Methods}

Titan organic aerosol synthesis and photochemistry experiment. Dicyanoacetylene $\left(\mathrm{C}_{4} \mathrm{~N}_{2}\right)$ was synthesized according to a well-established procedure reported in the literature ${ }^{48,49}$. These molecules are highly unstable and hazardous. Hence we developed a synthesis laboratory adjacent to the spectroscopy and photochemistry lab. $\mathrm{C}_{4} \mathrm{~N}_{2}$ was prepared and used immediately to make ice films at $100 \mathrm{~K}$. During the vapour deposition of $\mathrm{C}_{4} \mathrm{~N}_{2}$ on the cryogenic window (Sapphire or $\mathrm{KBr}$, both transmit ultraviolet and infrared for the $\mathrm{CN}$ stretch around $2,244 \mathrm{~cm}^{-1}$, sapphire cutoff is $\sim 1,600 \mathrm{~cm}^{-1}$, whereas $\mathrm{KBr}$ is transparent down to $450 \mathrm{~cm}^{-1}$ ), the sample window was kept at $100 \mathrm{~K}$. Bulk $\mathrm{C}_{4} \mathrm{~N}_{2}$ was kept at around $-30^{\circ} \mathrm{C}$ during the sublimation into the ice chamber and subsequently after the preparation of ice films, the $\mathrm{C}_{4} \mathrm{~N}_{2}$ container was removed from the vacuum line and was stored in an $-80^{\circ} \mathrm{C}$ ice chest or in a dry-ice container.

Details of the experimental system are shown in Supplementary Figs S2 and S3. The experimental system in which thin films of $\mathrm{C}_{4} \mathrm{~N}_{2}$ ices were generated consisted of a closed-cycle helium cryostat (Advanced Research Systems) that cooled the substrate window (Sapphire or $\mathrm{KBr}$ ). $\mathrm{C}_{4} \mathrm{~N}_{2}$ was deposited from gas phase onto the window cooled to $100 \mathrm{~K}$, a temperature relevant to Titan's lower atmosphere. All the irradiation experiments were done at $100 \mathrm{~K}$, and at the end of the experiments temperature was raised at $5 \mathrm{~K} \mathrm{~min}^{-1}$ to room temperature. Infrared spectra were collected during the entire warm-up. Optical configuration of the substrate, FTIR, fibre optics ultraviolet-visible spectrometers and irradiation lasers were such that sample was not moved during simulataneous ultraviolet and infrared spectral measurements or during laser irradiation (Supplementary Fig. S3). Growth of $\mathrm{C}_{4} \mathrm{~N}_{2}$ 


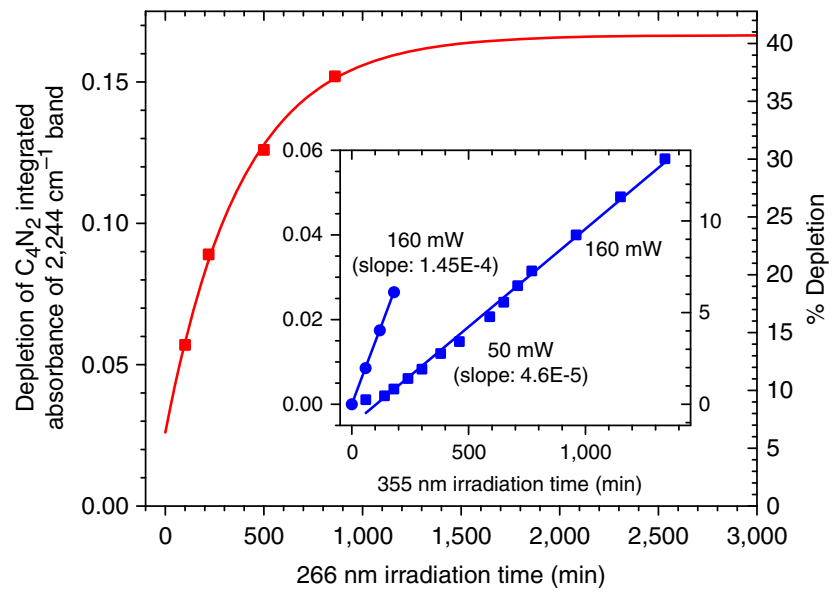

Figure 7 | Photodepletion kinetics of dicyanoacetylene ice. Time variation of change in absorption at $2,244 \mathrm{~cm}^{-1}$ when $\mathrm{C}_{4} \mathrm{~N}_{2}$ film at $100 \mathrm{~K}$ is photolysed at $355 \mathrm{~nm}$ (inset) and $266 \mathrm{~nm}$. As expected for a forbidden and weak singlet-triplet absorption-induced photochemistry, the depletion of $\mathrm{C}_{4} \mathrm{~N}_{2}$ is linearly proportion to the irradiation time when exposed at $355 \mathrm{~nm}$, representing initial stages of an exponential process. Only $14 \%$ of $\mathrm{C}_{4} \mathrm{~N}_{2}$ was depleted after $\sim 1,400 \mathrm{~min}$ irradiation at $\sim 50 \mathrm{~mW} \mathrm{~cm}^{-2}$. The last three points on the lower curve (filled squares) were obtained using higher laser power $\left(160 \mathrm{~mW} \mathrm{~cm}^{-2}\right.$ or $8 \mathrm{~mJ}$ per pulse), whereas the rest of the data were derived using a $50 \mathrm{~mW} \mathrm{~cm}^{-2}(2.5 \mathrm{~mJ}$ per pulse) laser power. Linearity of this curve when fluence is converted to time clearly indicates that the $355 \mathrm{~nm}$ photochemistry is a one-photon process. We also plotted these three points with $160 \mathrm{~mW} \mathrm{~cm}^{-2}$ laser power separately (filled circles). As discussed in the text, the slopes of these two curves scale linearly with the laser fluencies-confirming that the $355 \mathrm{~nm}$ photochemistry is indeed a one-photon process. The $266 \mathrm{~nm}$ photolysis through singlet-singlet excitation follows a monoexponential curve with over $35 \%$ depletion within the first $800 \mathrm{~min}$ of irradiation at $120 \mathrm{~mW} \mathrm{~cm}^{-2}$. Extrapolation towards the longer durations of the $266 \mathrm{~nm}$ photolysis may not be accurate due to simultaneous increase in extinction of the film at this wavelength from the formation of new products.

films were controlled such that the $2,244 \mathrm{~cm}^{-1}$ infrared absorption band reached an absorbance of $\sim 0.1$. This process ensured that enough material was deposited to allow measurable photoprocessing, but not too much material that would result in nonlinear absorption properties ( $>1.0 \mathrm{Abs}$ ) or scattering. Both the laser beam and the infrared beam from the FTIR spectrometer illuminated the whole $\sim 20 \mathrm{~mm}$ sapphire window and the $\mathrm{C}_{4} \mathrm{~N}_{2}$ film, while ultraviolet-visible spectra were collected from a $\sim 5 \mathrm{~mm}$ diameter area in the centre of the window. To avoid inducing additional photoprocessing due to ultraviolet light that may interfere with the kinetic analysis, we did not monitor the sample evolution using ultraviolet spectra, but instead used the mid-infrared band at $2,244 \mathrm{~cm}^{-1}$. We used the sapphire window for its excellent optical quality in the ultraviolet-visible spectral region $(>180 \mathrm{~nm})$ all the way into the mid-infrared $\left(>1,600 \mathrm{~cm}^{-1}\right)$, enabling simultaneous ultraviolet and infrared spectroscopy. In few experiments we used $\mathrm{KBr}$ substrate, gaining access to the infrared $\left(>500 \mathrm{~cm}^{-1}\right)$ at the cost of ultraviolet spectra. In these studies, other strong infrared bands of $\mathrm{C}_{4} \mathrm{~N}_{2}$ (738 and

$1,160 \mathrm{~cm}^{-1}$ ) with relative peak heights of $\sim 10 \%$ compared with the $2,244 \mathrm{~cm}^{-1}$ band, as well as a number of very weak combination bands between 2,250 and $3,400 \mathrm{~cm}^{-1}$ were observed (Supplementary Fig. S4), in accordance with earlier studies of $\mathrm{C}_{4} \mathrm{~N}_{2}$ in $\mathrm{Ar}$ matrices ${ }^{50}$. For this reason, we used the strongest $2,244 \mathrm{~cm}^{-1}$ $\mathrm{CN}$ asymmetric stretch band for quantitative data analysis. Ultraviolet and FTIR spectra were measured on $\mathrm{C}_{4} \mathrm{~N}_{2}$ ice at $100 \mathrm{~K}$ simultaneously on the same sample around the same time, enabling a good comparison between the ultraviolet and infrared spectra. While increasing scattering was observed with increasing ice thickness in the FTIR spectra, ultraviolet spectra were a convolution of electronic absorption and interference due to reflections caused by the $\mathrm{C}_{4} \mathrm{~N}_{2}$ ice film on the sapphire window. These interference modulations were used to derive film thickness assuming a refractive index of 1.45 , typical of many refractory organics such as polycyclic aromatic hydrocarbons (PAHs).

Laser and lamp photochemistry. A Nd-YAG laser (Quantel Brio) with second, third and fourth harmonic generation at 532, 355 and $266 \mathrm{~nm}$ was used for photochemistry. Laser light was defocused as explained below to avoid multiphoton processes such as resonance-enhanced multiphoton ionization or twophoton excitation into electronically excited states. Under solar radiation conditions such multiphoton absorption processes are negligible and in the laboratory these processes must be avoided to have a valid Titan simulation. The diameter of laser light was initially $\sim 5 \mathrm{~mm}$. A $10 \mathrm{~cm}$ focal length quartz biconvex lens was placed at $\sim 50 \mathrm{~cm}$ from the cryostat to result in a beam diameter of $\sim 20 \mathrm{~mm}$ on the optical window containing $\mathrm{C}_{4} \mathrm{~N}_{2}$ sample. Photon fluxes used in these experiments were typically $\sim 1 \times 10^{17}, \sim 3 \times 10^{16}$ and $\sim 5 \times 10^{16}$ photons $\mathrm{cm}^{-2} \mathrm{~s}^{-1}$ at 532, 355 and $266 \mathrm{~nm}$, respectively, before defocusing. A ultraviolet-visible absorption spectrograph (Ocean Optics USB4000) was used to detect optical changes between 200 and $1,000 \mathrm{~nm}$, a FTIR spectrometer (Thermo Nicolet 6700) covering 1 micron to 20 microns (10,000 to $500 \mathrm{~cm}^{-1}$ ), sapphire substrate cutoff $\sim 1,600 \mathrm{~cm}^{-1}$. Though the substrate window could be rotated around $360^{\circ}$ in the vacuum chamber, to enhance the accuracy of spectral changes, the organic film substrate window was kept in the same position during the entire experiment (after initial deposition) enabling simultaneous laser irradiation, ultraviolet and infrared spectral measurements.

\section{References}

1. Lane, A. L. et al. Photopolarimetry from Voyager-2-preliminary-results on Saturn, Titan, and the rings. Science 215, 537-543 (1982).

2. Rannou, P. et al. Titan haze distribution and optical properties retrieved from recent observations. Icarus 208, 850-867 (2010).

3. Stephan, K. et al. Specular reflection on Titan: liquids in Kraken Mare. Geophys. Res. Lett. 37, 5 (2010).

4. Lorenz, R. D. et al. The sand seas of Titan: Cassini RADAR observations of longitudinal dunes. Science 312, 724-727 (2006).

5. Khare, B. N. et al. Amino-acids derived from Titan tholins. Icarus 68, 176-184 (1986).

6. Sagan, C. \& Khare, B. N. Tholins-organic-chemistry of inter-stellar grains and gas. Nature 277, 102-107 (1979)

7. Vuitton, V., Yelle, R. V., Lavvas, P. \& Klippenstein, S. J. Rapid association reactions at low pressure: impact on the formation of hydrocarbons on Titan. Astrophys. J. 744, Article No. 11 (2012).

8. Lavvas, P., Sander, M., Kraft, M. \& Imanaka, H. Surface chemistry and particle shape: processes for the evolution of aerosols in Titan's atmosphere. Astrophys. J. 728, Article No. 80 (2011).

9. West, R. A. et al. The evolution of Titan's detached haze layer near equinox in 2009. Geophys. Res. Lett. 38, Article No. L06204 (2011).

10. Tomasko, M. G. et al. A model of Titan's aerosols based on measurements made inside the atmosphere. Planet Space Sci. 56, 669-707 (2008).

11. Dimitrov, V. \& Bar-Nun, A. Aging of Titan's aerosols. Icarus 156, 530-538 (2002).

12. Dimitrov, V. \& Bar-Nun, A. Hardening of Titan's aerosols by their charging. Icarus 166, 440-443 (2003)

13. Liang, M.-C., Yung, Y. L. \& Shemansky, D. E. Photolytically generated aerosols in the mesosphere and thermosphere of Titan. Astrophys. J. 661, L199-L202 (2007).

14. Lavvas, P. P., Coustenis, A. \& Vardavas, I. M. Coupling photochemistry with haze formation in Titan's atmosphere, Part II: results and validation with Cassini/Huygens data. Planet Space Sci. 56, 67-99 (2008).

15. Lavvas, P., Griffith, C. A. \& Yelle, R. V. Condensation in Titan's atmosphere at the Huygens landing site. Icarus 215, 732-750 (2011).

16. Lavvas, P. et al. Energy deposition and primary chemical products in Titan's upper atmosphere. Icarus 213, 233-251 (2011).

17. Toublanc, D. et al. Photochemical modeling of titans atmosphere. Icarus 113, 2-26 (1995).

18. Wilson, E. H. \& Atreya, S. K. Current state of modeling the photochemistry of Titan's mutually dependent atmosphere and ionosphere. J. Geophys. Res.Planets 109, Article No. E06002 (2004).

19. Anderson, C. M. \& Samuelson, R. E. Titan's aerosol and stratospheric ice opacities between 18 and $500 \mu \mathrm{m}$ : vertical and spectral characteristics from Cassini CIRS. Icarus 212, 762-778 (2011).

20. Teanby, N. A. et al. Titan's stratospheric $\mathrm{C}_{2} \mathrm{~N}_{2}, \mathrm{C}_{3} \mathrm{H}_{4}$, and $\mathrm{C}_{4} \mathrm{H}_{2}$ abundances from Cassini/CIRS far-infrared spectra. Icarus 202, 620-631 (2009).

21. Vuitton, V., Yelle, R. V. \& Cui, J. Formation and distribution of benzene on Titan. J. Geophys. Res.-Planets 113, Article No. E05007 (2008).

22. Lavvas, P., Yelle, R. V. \& Griffith, C. A. Titan's vertical aerosol structure at the Huygens landing site: constraints on particle size, density, charge, and refractive index. Icarus 210, 832-842 (2010).

23. Pilling, S., Andrade, D. P. P., Neto, A. C., Rittner, R. \& de Brito, A. N. DNA nucleobase synthesis at Titan atmosphere analog by soft X-rays. J. Phys. Chem. A 113, 11161-11166 (2009).

24. Cable, M. L. et al. Titan tholins: simulating Titan organic chemistry in the Cassini-Huygens era. Chem. Rev. 112, 1882-1909 (2011).

25. Raulin, F., Brasse, C., Poch, O. \& Coll, P. Prebiotic-like chemistry on Titan. Chem. Soc. Rev. 41, 5380-5393 (2012). 
26. Marcus, R. A. On theory of shifts and broadening of electronic spectra of polar solutes in polar media. J. Chem. Phys. 43, 1261-126 (1965).

27. Gudipati, M. S. Exciton, exchange, and through-bond interactions in multichromophoric molecules: an analysis of the electronic excited states. $J$. Phys. Chem. 98, 9750-9763 (1994).

28. Kasha, M. Characterization of electronic transitions in complex molecules. Discuss Faraday Soc. 9, 14-19 (1950).

29. Klessinger, M. \& Michl, J. Excited States and Photochemistry of Organic Molecules (VCH, 1995).

30. Samuelson, R. E., Mayo, L. A., Knuckles, M. A. \& Khanna, R. J. $\mathrm{C}_{4} \mathrm{~N}_{2}$ ice in Titan's north polar stratosphere. Planet Space Sci. 45, 941-948 (1997).

31. Coustenis, A., Schmitt, B., Khanna, R. K. \& Trotta, F. Plausible condensates in Titan's stratosphere from Voyager infrared spectra. Planet Space Sci. 47, 1305-1329 (1999)

32. Coll, P., Guillemin, J. C., Gazeau, M. C. \& Raulin, F. Report and implications of the first observation of $\mathrm{C}_{4} \mathrm{~N}_{2}$ in laboratory simulations of Titan's atmosphere. Planet Space Sci. 47, 1433-1440 (1999).

33. Khlifi, M. et al. Gas infrared spectra, assignments, and absolute IR band intensities of $\mathrm{C}_{4} \mathrm{~N}_{2}$ in the $250-3500 \mathrm{~cm}(-1)$ region: implications for Titan's stratosphere. Spectrochim. Acta A-Mol. Biomol. Spectrosc. 53, 707-712 (1997).

34. de Kok, R., Irwin, P. G. J. \& Teanby, N. A. Far-infrared opacity sources in Titan's troposphere reconsidered. Icarus 209, 854-857 (2010).

35. de Kok, R. et al. Characteristics of Titan's stratospheric aerosols and condensate clouds from Cassini CIRS far-infrared spectra. Icarus 191, 223-235 (2007).

36. Fischer, G., Johnson, G. D., Ramsay, D. A. \& Ross, I. G. Electronic spectrum of dicyanoacetylene. 2. Interpretation of the 2800 A transition. J. Phys. Chem. A 107, 10637-10641 (2003).

37. Fischer, G. \& Ross, I. G. Electronic spectrum of dicyanoacetylene. 1. Calculations of the geometrics and vibrations of ground and excited states of diacetylene, cyanoacetylene, cyanogen, triacetylene, cyanodiacetylene, and dicyanoacetylene. J. Phys. Chem. A 107, 10631-10636 (2003).

38. Miller, F. A. \& Hannan, R. B. The ultraviolet absorption spectrum of dicyanoacetylene. Spectrochim. Acta 12, 321-331 (1958).

39. Benilan, Y. et al. Temperature dependence of $\mathrm{HC} 3 \mathrm{~N}, \mathrm{C} 6 \mathrm{H} 2$, and $\mathrm{C} 4 \mathrm{~N} 2$ mid-UV absorption coefficients. Application to the interpretation of Titan's atmospheric spectra. Astrophys. Space Sci. 236, 85-95 (1996).

40. Smith, A. M., Schallmoser, G., Thoma, A. \& Bondybey, V. E. Infrared spectral evidence of Nc-Cc-Nc-photoisomerization of Nc-Cc-Cn in an Argon matrix. J. Chem. Phys. 98, 1776-1785 (1993).

41. Imanaka, H. et al. Laboratory experiments of Titan tholin formed in cold plasma at various pressures: implications for nitrogen-containing polycyclic aromatic compounds in Titan haze. Icarus 168, 344-366 (2004).

42. Imanaka, H., Cruikshank, D. P., Khare, B. N. \& McKay, C. P. Optical constants of Titan tholins at mid-infrared wavelengths $(2.5-25 \mu \mathrm{m})$ and the possible chemical nature of Titan's haze particles. Icarus 218, 247-261 (2012).

43. Kolos, R., Zielinski, Z., Grabowski, Z. R. \& Mizerski, T. Dicyanoacetylene photodissociation at $193-\mathrm{nm}$ and at $248-\mathrm{nm}$ studied by transient absorptionspectroscopy-production of $\mathrm{CN}, \mathrm{C}_{2}$ and $\mathrm{C}_{3} \mathrm{~N}$. Chem. Phys. Lett. 180, 73-80 (1991).

44. Crepin, C. et al. UV-induced growth of cyanopolyyne chains in cryogenic solids. Phys. Chem. Chem. Phys. 13, 16780-16785 (2011).

45. Lindquist, B. A. \& Corcelli, S. A. Nitrile groups as vibrational probes: calculations of the $\mathrm{CN}$ infrared absorption line shape of acetonitrile in water and tetrahydrofuran. J. Phys. Chem. B 112, 6301-6303 (2008).
46. Atkins, P. \& de Paula, J. Atkins' Physical Chemistry 9th edn (Oxford University Press, 2009).

47. Lavvas, P. P., Coustenis, A. \& Vardavas, I. M. Coupling photochemistry with haze formation in Titan's atmosphere, part I: Model description. Planet Space Sci. 56, 27-66 (2008)

48. Coupeaud, A., Pietri, N., Couturier-Tamburelli, I. \& Aycard, J. P. $\mathrm{NC}_{4} \mathrm{NC}_{2}$ : a new isomer of dicyanodiacetylene isolated in a cryogenic matrix. Chem. Phys. Lett. 416, 349-353 (2005).

49. Ciganek, E. \& Krespan, C. G. Syntheses of dicyanoacetylene. J. Organic Chem. 33, 541-554 (1968).

50. Guennoun, Z., Couturier-Tamburelli, I., Pietri, N. \& Aycard, J. P. UV photoisomerisation of cyano and dicyanoacetylene: the first identification of $\mathrm{CCNCH}$ and $\mathrm{CCCNCN}$ isomers-matrix isolation, infrared and ab initio study. Chem. Phys. Lett. 368, 574-583 (2003).

\section{Acknowledgements}

The Jet Propulsion Laboratory (JPL) part of the work is partly supported by several of the following funding sources: NASA Astrobiology Institute team 'Titan as a Prebiotic Chemical System', the Jet Propulsion Laboratory Director's Research and Development Fund and the JPL Research and Technology Development funding for the infrastructure of the Ice Spectroscopy Laboratory (ISL) and Titan organic aerosol spectroscopy and chemistry (TOAST) laboratory at JPL. The University of Provence part of the work was funded by the French national program Environnements Planétaires et Origines de la Vie (EPOV). This research was carried out at the Jet Propulsion Laboratory, California Institute of Technology, under a contract with the National Aeronautics and Space Administration.

\section{Author contributions}

M.S.G. and M.A. conceived the research ideas and wrote a significant part of the publication. M.S.G. coordinated the research activity, put the team together, involved in conducting the experiments, data analysis and data interpretation. R.J. and A.L. contributed to build infrastructure of the laboratory needed to synthesize the materials, conducted synthesis under the guidance of I.C. and majority of experiments described in this publication under the guidance of M.G. I.C. conducted the research in Marseille, France, as well as guided the synthesis and a part of photochemical investigations at JPL. R.J. performed the work as a NASA Post Doctoral Fellow at the Jet Propulsion Laboratory. A.L. performed a part of this work at the Jet Propulsion Laboratory during Academy of Finland fellowship.

\section{Additional information}

Supplementary Information accompanies this paper at http://www.nature.com/ naturecommunications

Competing financial interests: The authors declare no competing financial interests.

Reprints and permission information is available online at http://npg.nature.com/ reprintsandpermissions/

How to cite this article: Gudipati, M. S. et al. Photochemical activity of Titan's low-altitude condensed haze. Nat. Commun. 4:1648 doi: 10.1038/ncomms2649 (2013). 